\title{
Ecological Strategies of Urban Ecological Parks - A case of Bishan Ang Mo Kio Park and Kallang River in Singapore
}

\author{
Zhongfang $\mathrm{An}^{1}$, Qingchang Chen ${ }^{1, *}$, and Jian $\mathrm{Li}^{1}$ \\ ${ }^{1}$ Shanghai Institute of Technology, College of Urban Construction and Safety Engineering, 201418 Shanghai, China
}

\begin{abstract}
In order to deal with the negative effect of ecological environment caused by the rapid urbanization process, much more attention has been paid to urban ecological parks with the functions such as restoring urban natural ecological environment, building sustainable stable ecosystems, improving biodiversity and spreading ecological culture. On the basis of explaining the concept of urban ecological parks, this paper sums up the ecological strategies of the restoration case of Bishan Ang Mo Kio Park and Kallang River in Singapore, and puts forward ecological strategies of urban ecological parks in the aspects of planning, design and maintenance, involving site selection, layout, planting, techniques, facilities, education and management.
\end{abstract}

The rapid urbanization process has caused much more serious ecological environmental degeneration while promoting rapid economic growth and improving people's living standards, which is in conflict with the high requirements of living environmental quality and ecological environmental conservation. In the 1970s, with the launch of UNESCO's Man and the Biosphere Programme (MAB), the activities of urban natural conservation and ecological restoration have been carried out worldwide [1]. Different from traditional urban parks, urban ecological parks not only have the functions such as rest, communication and sightseeing, but also have the ecological functions such as restoring urban natural ecological environment, building sustainable stable ecosystems, improving biodiversity and spreading ecological culture. To sum up, with the comprehensive benefits in the aspects of ecology, landscape, society and culture, urban ecological parks have been highly praised. However, in actual practice, there are some problems such as applying the experience of traditional urban parks in the planning, design and maintenance of urban ecological parks, difficulties in actual process of construction and high costs of maintenance. Therefore, it is urgent to study the ecological strategies of urban ecological parks in the aspects of planning, design and maintenance.

\section{Concept of urban ecological parks}

Urban ecological parks refer to the parks which make full use of wasteland or abandoned land in the urban areas or suburban areas, comprehensively apply the principles of ecology and landscape ecology, retain or imitate regional natural habitats to create natural ecological environment and provide sites for activities such as rest, sightseeing and practice harmonious with natural ecological process
$[1,2]$. With the main goal of protecting or building regional diverse self-succession ecosystems, urban ecological parks are able to effectively alleviate the contradiction between the development of people's living standards and much more serious ecological environmental degeneration, restore urban natural ecological environment, build stable sustainable ecosystems and finally promote the harmonious coexistence between human and natural environment.

\section{A case of Bishan Ang Mo Kio Park and Kallang River in Singapore}

\subsection{Background of Project}

As an island city located in the tropical region, Singapore has relatively abundant rainfall (annual rainfall is about $2400 \mathrm{~mm}$ ). Nevertheless, due to the lack of sufficient fresh water resources and natural underground aquifer, the land actually used to collect and store rainwater is extremely limited $[3,4]$. In the $1960 \mathrm{~s}$, in order to deal with a series of environmental problems such as floods, droughts and severe water pollution caused by rapid economic development and population explosion, Singapore embarked on a wide range of construction activities that natural water systems were transformed into concrete culverts and drainage channels. There was no doubt that as the longest river in Singapore, Kallang River was transformed into drainage channels at some key points.

Built in 1988, Bishan Ang Mo Kio Park was an urban green buffer between Bishan new residential areas and Ang Mo Kio residential areas and one of the most popular urban parks in Singapore. Unfortunately, the transformed drainage channels of Kallang River flowed through the

\footnotetext{
*orresponding author: $\underline{\text { Cqc@sit.edu.cn }}$
} 
park and separated the park from the communities on both sides.

In 2006, Public Utilities Board (PUB) of Singapore launched the Active, Beautiful, Clean Waters (ABC Waters) Programme to improve water and life by harnessing the full potential of water [5]. As one of the critical practices of the Programme, Kallang River flowing through Bishan Ang Mo Kio Park had main design goals of restoring natural ecological rivers, organically integrating the park with surrounding environment, improving biodiversity and creating space close to nature.

\subsection{Ecological Strategies of Project}

\subsubsection{Restoring riverbanks by soil bioengineering techniques}

The ecological restoration of the riverbanks of Kallang River was the first time to use soil bioengineering techniques in tropical areas. Combing vegetation, natural materials with civil engineering techniques, the soil bioengineering techniques are able to stabilize riverbanks and prevent water from loss and soil from erosion, adapting to the continuous change of the environment. By using these techniques, a 2,700 meters long, 17-24 meters wide, straight concrete drainage channel has been restored into a 3,200 meters long, 100 meters wide, sinuous natural river meandering through the park (Figure 1), creating good ecological habitats for related vegetation and animals (biodiversity has increased by $30 \%$ ) and providing tourists with more space close to water for sightseeing and recreation. Additionally, by integrating the park with the river, the instantaneous rainwater generated by heavy rainfall was able to flow into the downstream of the river through the park adjacent to the land, improving the capacity of flood control and drainage (river drainage capacity has increased by $40 \%$ ).
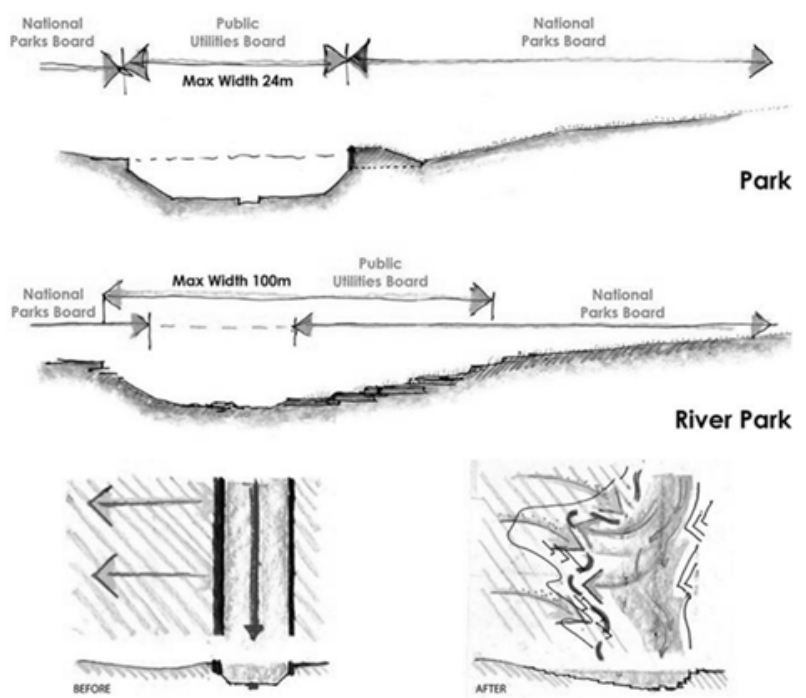

Fig. 1. The transition from park to river park (retrieved from https://www.asla.org/2016awards/169669.html.)

\subsubsection{Purifying and recycling rainwater}

Located upstream of the entire park, four artificial platform-type wetlands that used to be ponds at different levels in the park have built a well-run rainwater purification system. With wetland vegetation filtering pollutants and absorbing nutrients, the four artificial platform-type wetlands not only beautified the park but also reduced the pollution of rainfall runoff. After being disinfected by ultraviolet light, the purified rainwater flowed into the water park used for sightseeing and recreation. Eventually, the rainwater flowed back to the wetlands for purification again. The whole process made the rainwater fully purified and recycled, saving valuable water resources.

\subsubsection{Recycling waste materials}

In accordance with the inherent material properties, waste materials were recycled for the reconstruction of the park, which not only reduced the consumption of raw materials but also saved the transportation cost of raw materials. For instance, the removed concrete drainage channels were reused for a stepped observation deck in accordance with site characteristics. What's more, branches, scrap metal and broken glass were reused for playgrounds, tables and landscape elements. In addition, sewage pipelines were reused as chairs and building waste materials were broken up and then reused as permeable layers.

\subsubsection{Designing secure riverbanks}

As water level sharply rises during storm period and falls during drought period, the sites for activities along the riverbanks vary from time to time. To ensure the safety of tourists along the riverbanks, comprehensive devices such as a river detection and water level warning system, warning lights, warning sirens and voice notification devices were installed in the park. Besides, warning signs, red markers and safety lines with buoys were installed at selected locations along the riverbanks. When a heavy rain comes or water level rises to a safe point, the river detection system will trigger warning lights, sirens and voice notification devices to remind tourists in the park to stay away from areas with red markers. Additionally, when receiving warning reminder, tourists will have necessary time to timely evacuate. Even if a heavy rain comes, the water in the river will slowly fill up, allowing tourists to safely stay away from the riverbanks to higher places.

\subsubsection{Integrating the park with surrounding environment}

Similar to Central Park in New York, the park is surrounded by densely populated residential areas. Therefore, there is no doubt that the park is a good place for tourists to contact and return to nature. In older to make it convenient for tourists to arrive at and enter into the park, roads access to the park were constructed and 
the number of entrances and exits increased. Besides, there is no fence between the park and the surrounding residential areas, allowing tourists to access to the park anytime and making landscape resources better shared.

\subsubsection{Organizing space In accordance with site characteristics}

In this case, the service function of the park was improved and enhanced. According to tourists' long-term fixed living habits, some specific space was reserved, existing sites were repaired and facilities were optimized, effectively minimizing unnecessary works. Besides, by combing tourists' social characteristics with the existing environmental characteristics of each site, some space for activities with varieties of themes was added to meet the needs of different tourists.

\subsubsection{Strengthening community participation and ecological education}

By organizing school-age children to design art patterns for playgrounds and holding family fun tours activities in the morning on weekend after the restoration of the park, community participation was implemented in the park. What's more, various ecological education activities were held in combination with the ecological design of the park, such as organizing tourists to observe the ecological transformation process of the park and the river, inviting them to monitor physical conditions of the river and introducing horticulture to the park. In addition, ecological education activities were strengthened in details in the park. For example, the signs on tree trunks that read "Think twice before setting lives free" can be seen everywhere, instructing the public to be kind to animals.

\section{Ecological strategies of urban ecological parks}

\subsection{Selecting site of project reasonably}

Urban ecological parks take the protection of urban natural ecological environment as their core task. In the aspect of site selection, on the basis of the factors that influence the site selection of traditional urban parks, such as service radius, accessibility and natural ecological environment, the "patch-corridor-matrix" model in landscape ecology should also be taken into account. In order to make full use of the "patch" function of urban ecological parks, attention should be paid to the key point of urban ecological strategies in the aspect of site selection, involving the interconnections, distribution patterns and landscape indicators of the key points [6]. To sum up, it is crucial to integrate the site selection of urban ecological parks with the construction of whole urban mountain-river pattern and ecological pattern.

\subsection{Organizing space In accordance with site characteristics}

The planning and design of urban ecological parks should not ignore site characteristics or lay too much stress on graphic composition. On the contrary, it is important to take advantage of nature, fully respect and utilize the existing site resources. For instance, characteristic well-grown vegetation in the sites can be used to create unique landscape space. What's more, a variety of space lower or higher than the ground can be created in accordance with site characteristics and water systems should be smoothened in the sites to connect and activate each space.

\subsection{Building natural vegetation communities}

The planning and design of urban ecological parks should choose native and zonal vegetation adapting to local climate with strong stress resistance and play the role of vegetation in ecological succession to build vegetation communities close to nature with diverse species, complex structures and complex habitats with multiple types such as water, wetlands, grasslands and woodlands [2]. Besides, some vegetation providing food sources and habitats for wild animals should be rationally introduced to strengthen the positive role of urban ecological parks in improving biodiversity and coordinating human with natural environment.

\subsection{Using ecological techniques}

As the technical support for the implementation of ecological concept, ecological techniques play a critical role in the construction of urban ecological parks. For example, artificial wetlands and ecological floating island techniques can be used to purify polluted water so as to promote the recycling of water resources. What's more, soil bioengineering techniques can be used to strengthen the material exchange between aquatic and terrestrial environment, providing suitable growing environment for aquatic and terrestrial species and improving biodiversity.

\subsection{Using ecological facilities}

As facilities have indispensable service and sightseeing benefits, the ecological characteristics of facilities in the urban ecological parks also need taking into account. In the aspects of material selection and material utilization, natural and environment-friendly materials should be chosen and waste materials should be recycled. For instance, the stone and wood in the sites can be reused for trash cans and signs. Besides, surrounding building waste can be reused for landscape elements. In addition, in aspects of energy utilization, clean energy such as wind and solar energy should be fully utilized to build facilities such as solar street lamps and windmills. 


\subsection{Strengthening ecological education}

Integrating landscape esthetic with ecological benefits of parks, urban ecological parks have the innate advantage of holding ecological education activities. It is important to open part of space with ecological design for tourists' visit and sightseeing, which will create the space for ecological education activities. What' $\mathrm{s}$ more, various ecological education activities should be held for a long time, in which ecological knowledge can be taught and ecological culture can be spread and finally the awareness of harmonious coexistence between human and natural ecological environment can be aroused among tourists.

\subsection{Scientific maintenance and management}

Make full use of the power of nature and reduce the unnecessary interference of human factors to the natural ecological environment. In the aspect of vegetation management, the first is to ensure the natural growth posture of vegetation as far as possible and carry out natural pruning rationally if necessary. The second is to use fertilizer rationally to create and regenerate soil fertility. Conditions permitting, withered branches, fallen leaves and river silt can be used as base fertilizer for the growth of vegetation to realize the recycling of material. The third is to make full use of the interactions among ecological factors in the ecosystems to control pests and diseases in the growth process of vegetation with non-toxic biological control methods. In addition, by monitoring the physicochemical and biochemical indexes of the parks, analyzing the change of the species that indicate environmental status and studying the interactions among ecological factors [7], the ecological status of the parks can be evaluated to ensure the healthy and stable operation of the ecosystems.

\section{Conclusions}

As a successful ecological restoration case, the restoration case of Bishan Ang Mo Kio Park and Kallang River mainly indicated the ecological strategies of urban ecological parks in the aspects of design and maintenance. However, the ecological strategies in the aspect of planning also need taking into account. In conclusion, the construction of urban ecological parks in China should combine the experience of excellent domestic and foreign cases with the specific requirements of Chinese urban ecological parks and put ecological strategies into practice in the aspects of planning, design and maintenance, so as to maximize the comprehensive benefits of urban ecological parks in the aspects of ecology, landscape, society and culture.

\section{References}

1. Y. Deng, Chinese Landscape Architecture, Discussion on the development and conception of the urban ecological park, 12, 51-53 (2003) (in chinese)

2. Q.F. Zhang, J.Y. Zhang, Chinese Journal of Ecology, Discussion on urban ecological park, 21(3), 61-64 (2002) (in chinese)

3. Ministry of the Environment and Water Resource. The Issue [EB/OL]. https://www.mewr. gov.sg/topic/water-conservation.

4. World Resource Institute. World's 36 Most Water-Stressed Countries [R/OL]. http://www. wri.org/blog/2013/12/world\%E2\%80\%99s-36-mostwater-stressed-ciuntries.

5. Public Utilities Board (PUB). About ABC Waters [EB/OL]. https://www.pub.gov.sg/abc waters/about.

6. Y. Deng, Building Science, Research on urban eco-park location \& layout from viewpoint of landscape ecology, 24(3), 165-169 (2003) (in chinese)

7. J. Wang, Journal of Fujian Forestry Science and Technology, Discussion on the ecological construction and management of city parks, 33(2), 214-219 (2006) (in chinese) 